\title{
When Spreading HIV May Matter Most: The Unclassifiable Sexual Non-Identity Of Adolescent African American MSMW On Their Journey To Testing
}

Deymon X. Fleming, DHA, Central Michigan University, USA James A. Johnson, Ph.D., Central Michigan University, USA Le'Roy E. Reese, Ph.D., Morehouse School of Medicine, USA Daniel E. Walker, Ph.D., University of Southern California, USA

\begin{abstract}
Recent studies have found that many young African American men who have sex with men and women (MSMW) do not identify as bisexual or non-heterosexual. The present study explored the mental journeys of twenty African American MSMW as they decided to undergo HIV testing. The rejection of sexual identity labels may contribute to the rising annual HIV infection rate among African American men who have sex with men (MSM) and MSMW. Furthermore, sexual identity ambivalence may lead to secretive sexual behavior and failure to disclose homosexual relations to female partners, behavior colloquially referred to as "down-low." Greater understanding of the nuanced distinctions between sexual identity and behavior may help public health researchers address the needs of this racial and sexual minority that remains especially vulnerable to HIV/AIDS.
\end{abstract}

Keywords: HIV; African American; Identity; Testing; Bisexual; MSMW

\section{INTRODUCTION}

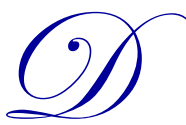

espite answering a recruitment flyer asking specifically for men who have sex with men and women, one interview participant in this study exclaimed, "Gays are gays, and straights are straights, but what's a bisexual? There's nobody here who's a bisexual!" (Fleming, 2013b).

His tone of voice was sincere and he evidently wanted to explicitly distance himself from the label of bisexuality. However, he and others like him reconciled their sexual identities with their sexual behavior as MSMW which was yet to be understood in the context of this study.

\section{CONTEXT OF THE ORIGINAL STUDY}

The primary purpose of the present study was to investigate the mental journeys of young African American MSMW as they navigated the decision to undergo HIV testing. However, he and others like him reconciled their sexual identities with their sexual behavior as MSMW which was yet to be understood in the context of this study. While all men were between 20-29 years of age at the time of the interviews, a majority of participants reported sexual debut in their preteen and early teenage years. These men reported many barriers and comparatively few catalysts to HIV testing throughout their lives, but especially during their teenage years (Fleming, 2013a).

This subpopulation was important to target because the HIV infection rate remains alarmingly high among African American MSM and MSMW. One critical factor in the intransigency of HIV infections is the fact that 
nearly $20 \%(\approx 240,000)$ of HIV-positive individuals $(\approx 1.2$ million people) in the United States do not know their HIV status (Centers for Disease Control and Prevention [CDC], 2012). Uninformed HIV-positive individuals engaging in unprotected sex have accounted for approximately 50\% of new HIV infections every year (Marks, Crepaz, \& Janssen, 2006) ${ }^{\mathrm{i}}$. A recent surveillance study of over 2,000 sexually active African American men, many within the 20-29 age group, revealed that MSMW engaged in more high-risk unprotected sex with male and female partners of negative and unknown HIV serostatus than did men who had sex exclusively with women (MSW) and MSM (Spikes et al., 2009). MSMW not only infect others in high-risk demographic groups, they provide a "bridge" for HIV to infect otherwise low-risk populations (Gorbach, Murphy, Weiss, Hucks-Ortiz \& Shoptaw, 2009). Understanding the thought processes and decision-making of MSMW is crucial for curbing the spread of HIV because these men can unwittingly expose themselves to HIV, as well as comparatively low-risk African American women (CDC, 2012) $)^{\mathrm{ii}, \mathrm{iii}}$.

\section{SHORTCOMINGS OF IDENTITY LABELS}

During the initial recruitment phase of the study, the word bisexual was chosen for recruitment flyers because it seemed purely descriptive, value-neutral, politically correct, and non-threatening. Yet, the investigator discovered this was a poor word choice for effectively reaching the population of interest. Time passed without any volunteers for the study, and an alternative recruiting approach was considered based on the ineffectiveness of the initial flyer. One of the pilot participants mentioned that the term bisexual was confusing, which prompted more careful examination of the potential word choice problem. The word bisexual was replaced with a clearer, if more explicit, question: "Have you participated in vaginal, anal, and/or oral sex with at least one man and one woman within the past 5 years?" Flyers containing the new language elicited many volunteers for the study, as well as piqued the researcher's curiosity about why such a simple change caused such a profound increase in the response rate.

The word bisexual was first used in 1824 to refer to hermaphrodites - individuals born with both male and female reproductive organs. By 1922, nearly one hundred years later, bisexual had evolved to describe sexual preference for both sexes (bisexual, 2010), and this has remained the accepted definition of the term. Today, researchers must parse the meaning of the word bisexual even further, clearly distinguishing bisexual behavior from bisexual identity because for many people the concepts of sexual behavior and identity have become unhitched from one another.

\section{DENIAL OF IDENTITY}

All participants in this study admitted to sexual encounters with both men and women, but were reluctant to claim a non-heterosexual identity. This fact was not fully appreciated at the beginning of the study. Instead, the separation of behavior and identity were better understood among study participants over the course of the participant interviews and data analysis. After nearly $75 \%$ of the interviews were completed, one participant was especially forthcoming in response to questions about how he felt about the term bisexual, particularly concerning bisexual identity.

PARTICIPANT: I think that'd make people not want to get tested. You know, if I was around somebody who, you know, just said, "Oh, I can't stand" or "I wouldn't want to be around somebody" - I know if there could be a possibility that I could be HIV - positive or I'm having sex with this person or that person, then I'm not going to go get tested because I'm not going to want to know.

INTERVIEWER: Right. And so - and how do you think it would impact bisexuals in gen specifically?

PARTICIPANT: I mean, I just think that, uh — I mean it do. It just makes you not want to get tested. And then more people have the virus and they're not taking care of themselves. And, you know, it's just being spread more. Like, you know, so I think it's a path in the wrong way, you know. But I mean it's just — just some people, I guess - you know, a lot of people - peer pressure, you know, they - I guess they just 
don't want to know because they don't want other people to single them out or make them feel, you know, uncomfortable or - you know, a lot of bisexual people like to have threesomes and stuff like that. And, you know, a lot of that go on. So, you know, they just do what they want to do, I guess. So, I mean, that's the best way I can - that's all I have to say (Fleming, 2013b).

This provided insight that stigma may be an important motivation for hiding non-heterosexual or nonhomosexual identity. Later in the study, another young man was asked where and how he would go about finding other partners (MSMW or otherwise) with whom to engage. He responded that he found them in local social clubs in the following way:

This was a - it was a down-low club. Well, it wasn't even a down-low club. It was a straight-up gay club with down-low people. Hide in the dark. That's what I do - hide in the dark, drink my drink. And then you just go about your target (Fleming, 2013b).

This implied that disguise and deception help some men, whether they identified with the label MSMW or not, to maintain an external heterosexual or homosexual identity, internalization of which may eventually lead to rejection of one's true sexual identity. The use of both the third person plural and the first person singular in his description suggested an inner conflict over identifying as down-low, and therefore bisexual.

This study examined the decision-making processes of HIV-negative and HIV-positive African American MSMW regarding HIV testing behavior. Efforts to understand the dynamics influencing how identity and behavior were cognitively preconceived in this population prompted a more intensive literature review regarding identity development and identification among persons who engage in same- and opposite-sex sexual relations. What became apparent as a result of this review was that MSMW who did not identify as non-heterosexual may fail to realize that their homosexual behavior places them at high risk for HIV infection. Without understanding the personal risk for contracting HIV by explicitly examining their sexual behavior, these MSMW may actively or passively avoid HIV testing. HIV-positive individuals who do not know their HIV status and who engage in highrisk behavior (sex or substance-related) can expose 2.5 other people every year on average (Marks et al., 2006). Therefore, the relationship between sexual identity and sexual behavior by MSMW may present a serious public health concern.

\section{CONFLATED SEXUAL IDENTITY AND BEHAVIOR ORIENTATION IN ACADEMIC RESEARCH}

To set aside the complex issues of sexual identity and focus exclusively on the behavior that increases the risk of HIV transmission, epidemiologists Glick, Muzyka, Salkin, and Lurie (1994) coined the acronym MSM to refer to men who have sex with men. Use of the related terms MSW and MSMW followed shortly after. In the context of the study described here, these terms are used based on their prominence in the HIV research literature, as they have been useful for delineating boundaries around different categories of male sexual behavior.

While sexual behaviors may be categorized discretely, attendant sexual identities and preferences are fluid (Young \& Meyer, 2005). This was especially true for the MSMW participants in this study. Their sexual experiences were quite complex, changed over time and informed their sexual identities as they matured. The majority of participants in this study reported sexual debut during their preteen or early teenage years (Fleming, 2013a). At the time of sexual debut, these men exclusively engaged in homosexual or heterosexual behaviors. Gradually, all participants came to engage in sexual behavior with both men and women. Over $80 \%$ of all African American men experience sexual debut by age seventeen (Cavazos-Rehg et al., 2009).

The formation of a sexual identity did not necessarily progress along the same trajectory as the behavioral process of becoming MSMW. Many men continued to maintain strictly heterosexual identities after engaging in homosexual relations or strictly homosexual identities after engaging in heterosexual relations (Fleming, 2013b). It was unclear whether this was intentional denial or simply a lack of motivation to form an explicit sexual identity. Operario, Smith, and Kegeles (2008) noted that some MSMW reject the bisexual identity because a nonheterosexual identity directly conflicts with their beliefs about masculinity. Some participants eventually accepted 
non-heterosexual identities, either self-labeling as bisexuals, down-low, or gay. These findings are in line with previous observations by Ford, Whetten, Hall, Kaufman, and Thrasher (2007).

In the United States, few people identify as bisexuals. Herbenick et al. (2010) reported that both male and female bisexuals made up just 3.1\% of the total Lesbian, Gay, Bisexual, and Transgender (LGBT) community and bisexual men made up just slightly more than $1 \%$ of the total United States population in 2008. The San Francisco Human Rights Commission (2010) suggested that these numbers are probably underestimates because bisexual identity can be hidden, distorted, denied, or misreported for a variety of reasons, including: assumptions by others, historical revisionism, exclusion, biphobia, eclipsed and conflated sexual orientation, economic discrimination, lack of institutional support, generational differences, and hidden diversity. Mosher, Chandra, and Jones (2005) confirmed this underestimation, reporting that nearly $6 \%$ of men admitted to having sex with both men and women, as compared with only $1 \%$ who claimed a bisexual identity. This provided further evidence that sexual behavior and identity has become unhitched among MSMW.

As described earlier, a subset of African American MSMW engage in surreptitious homosexual sex without the knowledge of their long-term female partners, known colloquially as "down-low" (Operario, Smith, Arnold, \& Kegeles, 2011; Wolitski, Jones, Wasserman, \& Smith, 2006). Millet, Malebranche, Mason, and Spikes (2005) asserted that a majority of African American MSMW are down-low, preferring to keep their sexual relationships with men secret from female partners, family, or friends. In analyzing non-gay African American men's narratives about their sexual behaviors, Operario et al. (2008) added, "cultural norms favor secrecy and privacy about any personal matters" (p. 347).

\section{THE FLUIDITY OF IDENTITY IN OTHER DIMENSIONS}

Time is not the only dimension of behavior and identity fluidity. Young and Meyer (2005) described poverty as another key dimension of the African American community. Farmer (2003) speculated that "males involved in prostitution are almost universally poor, and it may be their poverty, rather than their sexual preference, that puts them at risk of HIV infection. Many men involved in homosexual prostitution, particularly minority adolescents, do not necessarily identify as "gay" (p. 47). Young and Meyer (2005) posited that "the same-gender behavior among poor men of color (especially youth) is sex work rather than sex for pleasure and is devoid of identity and community" (p. 1145).

None of the participants in the present study admitted to prostitution, yet all had experienced poverty and most were poor during the interviews. Several participants clearly conveyed their awareness of potential, if not actual, high frequency sexual activity, sexual obsession, and perhaps even prostitution among peers. For example, two participants said that all they needed to do was to call a few phone numbers to be able to produce a roomful of eager sexual participants.

In adolescent males, other dimensions of fluidity may also exist. One of the strengths of the present study is that it highlighted the thought processes and sexual behaviors of teenage African American MSMW. While the participants were in their twenties at the time of the interviews, they all related stories of sexual activity from their teen years. Participants revealed that experimentation was prevalent in early adolescence, which is not uncommon for young people. Bisexual behavior during a period of exploration and experimentation may not influence identity formation as strongly as at other times.

Sexual assault during childhood also contributed to sexual identity formation of participants in this study. One participant described being seduced by an uncle after being drugged (Fleming, 2013b). While he chose to engage in predominantly homosexual behavior later in life, he remained staunchly opposed to identifying as a bisexual (Fleming, 2013b).

Some participants described having principally heterosexual or homosexual experiences with rare exceptions. Again, the aberrant sexual encounter with a member of the sex not usually preferred may not influence core sexual identity. The label of bisexual or even MSMW may fall short of accurately describing the nuances of these men's experiences. Furthermore, sexually active teenagers may not have sufficient experience to confidently 
form a sexual identity. Considering these circumstances, Young and Meyer (2005) expressed three objections to the ubiquitous use of labeling, saying that labeling:

(1) undermines the self-determined sexual identity of members of sexual-minority groups, in particular people of color; (2) deflects attention from social dimensions of sexuality that are critical in understanding sexual health; and (3) obscures elements of sexual behavior that are important for public health research and intervention (p. 1144).

\section{MSMW REASONS FOR IDENTITY DENIAL AMONG AFRICAN AMERICAN MSMW}

Young African American MSMW often engage in sexual behavior that increases the risk of HIV transmission to both male and female sexual partners, such as unprotected sex, sex with strangers, and high numbers of sexual partners. However, many of these men do not identify with labels such as bisexual or MSMW. There are several potential reasons for this disconnect between identify and behavior.

The definitions and usage of the terms MSM, MSW, and MSMW must be explored to ascertain whether these terms are truly simplifying behavioral patterns. Young and Meyer (2005) did not favor these terms, calling them, "problematic because they obscure social dimensions of sexuality; undermine the self-labeling of lesbian, gay, and bisexual people; and do not sufficiently describe variations in sexual behavior" (p. 1144). Young and Meyer argued that sexuality and identity are far more complex and nuanced and the overuse of these kinds of terms by public health professionals is fundamentally biased in that it, "adds to a history of scientific labeling that reflects, and inadvertently advances, heterosexual notions in discussing members of sexual-minority groups" (p. 1144).

Young and Meyer (2005) built their case by arguing that the creation of the MSM, MSW, and MSMW distinctions were driven by the concurrence of epidemiological and social construction perspectives. These terms, created to assist HIV research in the early 1990s, have become established in research and health programming because, "the terms held the promise of reducing AIDS stigma" (p. 1144).

The epidemiological perspective "sought to avoid complex social and cultural connotations that, according to a strict biomedical view, have little to do with epidemiological investigation of diseases" (Young \& Meyer, 2005, p. 1144). The terms MSM, MSW, and MSMW focused solely on behavior patterns "that placed individuals at risk for HIV infection, a particularly important distinction given that scientific and medical experts had initially identified gay identity as a risk for HIV/AIDS" (Young \& Meyer, 2005, p. 1144). Targeting homosexual identity rather than behavior encouraged stigmatization of lesbians, gays, and bisexuals, and stymied HIV prevention efforts (Treichler, 1999; Herek \& Glunt, 1988). Therefore, the shift to focus strictly on behavior was originally seen as a positive development.

In contrast to the epidemiological perspective, social construction theory sought "more textured understandings of sexuality that do not assume alignments among identity, behavior, and desire" (Young \& Meyer, 2005, p. 1144). Instead, social construction theory posits that sexual identity is a product of the social and cultural environmental influences. The conflict between these two perspectives may have diminished the usefulness of these labels as keys to categorizing sexual identity.

Results from the present study may reflect the shortcomings of sexual identity labels as motivators for seeking HIV testing among young African American MSMW. While epidemiologists attempted to negate the stigma attached to words such as gay or bisexual, the so-called neutral term MSMW nevertheless became associated with the stigma of homosexuality. In fact, the existence of the term MSMW may have prevented some participants from earlier testing, due to fear of social ostracism from their families, friends and community. One participant expressed this fear, saying:

You know, and, um, I think it's going to take a long while or maybe never for the bisexual people to really feel comfortable with it because so many people hate. - I think bisexual people are more hated than gays, you know (Fleming, 2013b). 
For twenty years, the labels MSM, MSW, and MSMW have been useful tools for epidemiologists and public health researchers fighting against the HIV/AIDS epidemic. The time may have come, however, for the elimination of these labels in favor of a clearer focus on the social protocol that promotes certain high-risk sexual behaviors. Clearly, a deeper understanding of the complex and fluid relationship between sexual behavior and identity is needed to employ effective HIV prevention strategies among young African American men.

\section{DISCUSSION}

The original focus of this study was to explore the mental journeys young African American men who have sex with men and women (MSMW) living in a large southeastern geographic area travelled on their way to getting tested for HIV. Consequently, the interview questions were not designed to directly address issues of sexual identity and behavior. Nevertheless, the inadvertent discovery that disconnection between sexual identity and sexual behavior is common among this particular sample could have important implications for public health officials working to stem the rise of HIV infection. These glimpses into the complex inner lives of African American MSMW suggest that further research focused on sexual identities is warranted. Research that seeks to identify and understand those determinants of sexual identity should be pursued to lend clarity on this topic and how it specifically informs HIV risk behavior. Furthermore, the following areas may help to inform the field's understanding of these phenomena: 1) determining whether identity-behavior disconnection is common among young African American males of all sexual identities who delay HIV testing until many years after sexual debut; 2) determining the relationship, if any, between identity ambiguity and the decision to seek HIV testing; 3) determining the personality characteristics of men who seek early HIV testing, versus those who delay HIV testing; and 4) examining whether there is a relationship between the dynamics of sexual identity formation in MSMW and the increases in the HIV infection rate among African American women.

\section{CONCLUSION}

Many young African American men who engage in high-risk sexual behavior with other men do not identify as bisexual or MSMW for a variety of reasons. For the participants in this study, fear of stigma and social ostracism was an extremely potent force that may have motivated the young African American men to avoid identifying as bisexual or MSMW. This population generally experienced early sexual debut as preteens or early teens, and may have been too psychologically and emotionally immature to deliberately form a sexual identity. A number of participants stated that their sexual encounters were predominately with members of one sex. Therefore, they identified as only heterosexual or homosexual and did not include the outlier encounters that behaviorally qualified them as MSMW.

Outside of this sample of participants, other factors may influence and encourage men to dissociate their sexual identity from their behavior. Drug addiction, prostitution, poverty, and incarceration are all interrelated circumstances that also increase the likelihood of high-risk sexual activity with both men and women. Some young men may refuse to allow actions which occur under such compromised circumstances to influence their core sexual identities.

Researchers and practitioners unaware of the complexities in the relationship between sexual behavior and sexual identity are advised to proceed carefully and attend to these potential confounds when working with this population. Sensitivity in the choice of labels - MSMW, bisexual, non-heterosexual, non-gay identified - is of utmost importance when communicating with members of this sexual minority. A deeper understanding of how sexual identity, regardless of sexual behavior, influences risk assessment and preventative behaviors is essential for curbing the spread of HIV/AIDS.

\section{AUTHOR INFORMATION}

Deymon X. Fleming, DHA, MPH. Dr. Fleming received his BA from the University of California, San Diego; MPH from Tulane School of Medicine and Tropical Health; DHA from Central Michigan University. Dr. Fleming has an extensive career managing public health programs domestically and internationally in topic areas that involved Sexually Transmitted Diseases, Tuberculosis, Childhood Immunizations, Guinea Worm Disease, Injury 
Prevention and Global AIDS. His research interests include HIV in disenfranchised communities and barriers to testing. He is the Senior Advisor for Program Development and Principal Management Official at the Centers for Disease Control in Atlanta, Georgia. E-Mail: twocold06@gmail.com or flemildx@cmich.edu (Corresponding author)

James A. Johnson, Ph.D., Dr. Johnson is a medical social scientist who specializes in international health systems and organizational development. He is a Professor of Health Administration and Policy in the School of Health Sciences Central Michigan University where he teaches comparative health systems, organizational behavior, international health, and systems thinking in the Doctor of Health Administration (DHA) Program. He also works closely with the World Health Organization (WHO) and ProWorld Service Corps on international projects. He is a Regular Delegate to the World Public Health Federation Congress and a member of the Global Health Council. . EMail: johns6ja@cmich.edu

Le'Roy E. Reese, Ph.D., Dr. Reese is an associate professor at Morehouse School of Medicine in the Department of Community Health and Preventive Medicine. Dr. Reese conducts community-based health research focused on the development on healthy lifestyles, the reduction of risk behaviors in under-resourced communities, and the modification of community based social determinants of health. He served on the Task Force of the American Psychological Association that produced the report Resilience and Strength in African American Children and Adolescents. A clinical psychologist, Dr. Reese also works clinically with children and their families from underserved communities. E-Mail: lreese@msm.edu

Daniel E. Walker, Ph.D., MA, Dr. Walker is a Research Associate with the Center for Religion and Civic Culture at the University of Southern California, Board Chair of the BLU Educational Foundation, and the President/CEO of Perfect Works, a consulting firm that uses history, faith, education, and the arts to bring progressive change to the world. Dr. Walker is the director of Good Neighbors, an initiative using faith leaders to address conflicts and build bridges between Latino and African American communities. E-Mail: drdanielwalker@hotmail.com

\section{REFERENCES}

1. Cavazos-Rehg, P. A., Krauss, M. J., Spitznagel, E. L., Schootman, M., Bucholz, K. K., Peipert, J. F., Bierut, L. J. (2009). Age of sexual debut among US adolescents. Contraception, 80(2), 158-162.

2. Centers for Disease Control and Prevention. (2012). HIV in the United States: At a Glance. Retrieved from http://www.cdc.gov/hiv/resources/factsheets/us.htm

3. Dictionary.com. (2014). Bisexual. Retrieved http://dictionary.reference.com/browse/bisexual

4. Farmer, P. (2003). Pathologies of power: Health, human rights, and the new war on the poor. Berkeley, CA: University of California Press.

5. Fleming, D. X. (2013a). Exploring factors and processes that influence the decision to get tested for HIV by African American adult men. Retrieved from ProQuest Dissertations and Theses. (AAT 3587769)

6. Fleming, D. X. (2013b). [Exploring factors and processes that influence the decision to get tested for HIV by African American adult men.] Unpublished raw data.

7. Ford, C. L., Whetten, K. D., Hall, S. A., Kaufman, J. S., \& Thrasher, A. D. (2007). Black sexuality, social construction, and research targeting "the Down-Low" ("the DL"). Annals of Epidemiology, 17(3), 209-216.

8. Glick, M., Muzyka, B. C., Salkin, L. M., \& Lurie, D. (1994). Necrotizing ulcerative periodontitis: A marker for immune deterioration and a predictor for the diagnosis of AIDS. Journal of Periodontology, 65(5), 393397.

9. $\quad$ Gorbach, P. M., Murphy, R., Weiss, R. E., Hucks-Ortiz, C., \& Shoptaw, S. (2009). Bridging sexual boundaries: Men who have sex with men and women in a street-based sample in Los Angeles. Journal of Urban Health: Bulletin of the New York Academy of Medicine, 86(Suppl 1), S63-S76. doi: 10.1007/s1152G-009-9370-7

10. Herbenick, D., Reece, M., Schick, V., Sanders, S. A., Dodge, B., \& Fortenberry, J. D. (2010). Sexual behavior in the United States: Results from a national probability sample of men and women ages 14-94. The Journal of Sexual Medicine, 7(Suppl 5), 255-265. 
11. Herek, G. M., \& Glunt, E. K. (1988). An epidemic of stigma - Public reactions toAIDS. The American Psychologist, 43(11), 886-891.

12. Hodder, S. L., Justman, J., Haley, D. F., Adimora, A. A., Fogel, C. I., Golin, C. E., \& El-Sadr, W. M. (2010). Challenges of a hidden epidemic: HIV prevention among women in the United States. Journal of Acquired Immune Deficiency Syndromes, 55(Suppl 2), S69-S73.

13. Marks, G., Crepaz, N., \& Janssen, R. S. (2006). Estimating sexual transmission of HIV from persons aware and unaware that they are infected with the virus in the USA. AIDS, 20(10), 1447-1450.

14. Millet, G., Malebranche, D., Mason, B., \& Spikes, P. (2005). Focusing "down-low": Bisexual black men, HIV risk and heterosexual transmission. Journal of the National Medical Association, 97 (Suppl 7), 52S59S.

15. Mosher, W. D., Chandra, A., \& Jones, J. (2005). Sexual behavior and selected health measures: Men and women 15-44 years of age, United States, 2002. Advance Data, (362), 1-55.

16. Operario, D., Smith, C. D., Arnold, E., \& Kegeles, S. (2011). Sexual risk and substance use behaviors among African American men who have sex with men and women. AIDS and Behavior, 15(3), 576-583.

17. Operario, D., Smith, C. D., \& Kegeles, S. (2008). Social and psychological context for HIV risk in nongay-identified African American men who have sex with men. AIDS Education and Prevention, 20(4), $347-$ 359.

18. San Francisco Human Rights Commission. (2010). Bisexual Invisibility: Impacts and Recommendations. Retrieved from http://www.sf-hrc.org/modules/showdocument.aspx?documentid=989

19. Spikes, P. S., Purcell, D. W., Williams, K. M., Chen, Y., Ding, H., \& Sullivan, P. S. (2009). Sexual risk behaviors among HIV-positive black men who have sex with women, with men, or with men and women: Implications for intervention development. American Journal of Public Health, 99(6), 1072-1078.

20. Treichler, P. A. (1999). How to have theory in an epidemic: Cultural chronicles of AIDS. Durham, NC: Duke University Press.

21. Wolitski, R. J., Jones, K. T., Wasserman, J. L., \& Smith, J. C. (2006). Self-identification as "down-low" among men who have sex with men (MSM) from 12 US cities. AIDS and Behavior, 10(5), 519-529.

22. Young, R. M., \& Meyer, I. H. (2005). The trouble with "MSM" and "WSW": Erasure of the sexualminority person in public health discourse. American Journal of Public Health, 95(7), 1144-1149.

\section{FOOTNOTES}

\footnotetext{
${ }^{\text {' }}$ Put another way, if the $20 \%$ of all HIV-positive people in the United States who do not know their HIV status were to become aware of their status, it has been estimated that there could be a reduction of up to 50\% in the total HIV population the following year, equal to 20,000-25,000 people. This means that each HIV-positive person who does not know their HIV status spreads their infection to 2.5 other people every year on average - a ratio that might be called the " $2.5 \mathrm{x}$ unknown HIV infection multiplier effect" (Marks et al., 2006).

${ }_{\text {ii }}$ Men who have sex with men and women not only suffer the highest rates of HIV infection but they also can transmit HIV to the wider population outside of those engaging in homosexual activity. African American women accounted for nearly two-thirds of the HIV diagnoses in 2010 even though they comprise only $12 \%$ of the total American female population (CDC, 2012).

iii For example, one recent study of 2,099 African American women presented findings that African American women living in six "hot spot" geographic areas-Atlanta, GA, Raleigh-Durham, NC, Washington, DC, Baltimore, MD, Newark, NJ, and New York City, NY-have HIV infection rates five times higher than the overall rate of HIV infection among African American women estimated by the CDC (Hodder et al., 2010).
} 